\title{
Improvement In The Strength Of Concrete By Using Industrial And Agricultural Waste
}

\author{
Pravin V Domke ${ }^{1}$ \\ ${ }^{I}$ (Department Of Civil Engineering, Rajiv Gandhi College of Engineering and Research Nagpur, Maharashtra, India,
}

\begin{abstract}
To redue the impact on the environnent due to industriel and agricultural waste products such as Rice Husk Ash (RHA)and (coconut fibers)COIR which are the waste products of paddy industry and agricultural industry.Use of these materials in concrete is not only improves the strength of concrete but also leads to the proper disposal of these materials, resulting in reducing the impact of these materials on environment. It is found that the rice husk ash is obtained by burning of rice husk in a controlled way,which is highly reactive pozzolonic material and the coir having excellent mechanical and physical properties to be utilized in effective way in developement of composite materials.this paper describes about the results obtained from the detailed investigation done on the partial replacement of cement with RHA cement concrete and shows clearly up to how much percentage the cement can be replaced by RHA and COIR.
\end{abstract}

\section{Keywords - Deflection, Flexural Strength, Coir, Compressive Strength, RHA Concrete, Split Tensile Strength.}

\section{INTRODUCTION}

Considerable efforts has been taken worldwide to utilize local natural waste and by-products materials as supplementary cementing materials to improve the properties of cement concrete as well as the use of these materials leads to the proper disposal of natural waste results in the less impact on environment in order to reduce the loss due to improper disposal of the waste. RHA is a bye-product of paddy industry obtained by controlled burning of rice husk and is a highly reactive pozzolanic material. On the other hand coir (coconut fiber) has excellent physical and mechanical properties and can be utilized more effectively in the development of composite materials.

Coconut fiber is one of the natural fibers abundantly available in tropical regions, and is extracted from the husk of coconut fruit. Not only the physical, chemical and mechanical properties of coconut fibers are shown; but also properties of composites (cement pastes, mortar and/or concrete etc), in which coconut fibers are used as reinforcement, are discussed. The aim of this review is to spread awareness of coconut fibers as a construction material in civil engineering. The

versatility and applications of coconut fibers in different fields is discussed in detail. Coconut fibers are reported as most ductile and energy absorbent material. It is concluded that coconut fibers have the potential to be

used in composites for different purposes. Since the use of coconut fibers has given some marvelous products, there is still possibility of the invention of new products containing coconut fibers with improved results. In civil engineering, coconut fibers have been used as reinforcement in composites for non-structural components. There is a need of investigating the behavior of coconut fiber reinforced concrete to be used in main structural components like beams and columns. Rice Husk is an agricultural waste obtained from milling of rice. About $10^{8}$ tones of rice husk is generated annually in the world. Meanwhile, the ash has been categorized under pozzolana, with about $67-70 \%$ silica and about $4.9 \%$ and $0.95 \%$ Alumina and iron oxides, respectively. The silica is substantially contained in amorphous form, which can react with the $\mathrm{CaOH}$ librated during the hardening of cement to further form cementations compounds. This can be used as an industrial raw material, for example, as an insulating material, fillers in plastics, building material, for making panel boards, activated carbon etc. Nowadays, production of white ash from rice husk is gaining importance as an excellent source of high grade amorphous silica for use in the ceramics, rubber and electronics industries. Exhaustive studies have been carried out on various aspects of rice husk whereas only very limited information on its physical and thermal properties is available.

\section{The objectives of present Study are}

1. To find the optimum mix design with regards to the amount of water, coir fibers, RHA and cement ratio required.

2.To investigate the physical properties of the RHA fiber reinforced concrete - density ( lightweight), strength (bending and compression), water absorption and moisture content.

3. Use of waste in a useful manner.

4. To provide economical construction material.

5. Provide safeguard to the environment by utilizing waste properly. 


\section{EXPERIMENTAL METHODOLOGY}

Experimental programme comprises of test on cement, RHA, COIR, cement concrete with partial replacement of cement with RHA and Coir.

\section{1 materials and mixture}

\section{proportions}

A .ordinary portland cement.

Ordinary Portland Cement confirming the requirements of IS 8112 : 1989 is used for the present experimental work.OPC 43 Grade cement is used.

\section{B. Rice Husk Ash}

Rice husk ash is prepared by burning of rice husk over

$700^{\circ} \mathrm{c}$ temperatures in a power plant as a fuel. RHA collected from the YASH AGRO INDUSTRIES LTD. Chimur.

TABLE 1: PHYSICAL PROPERTIES OF RHA

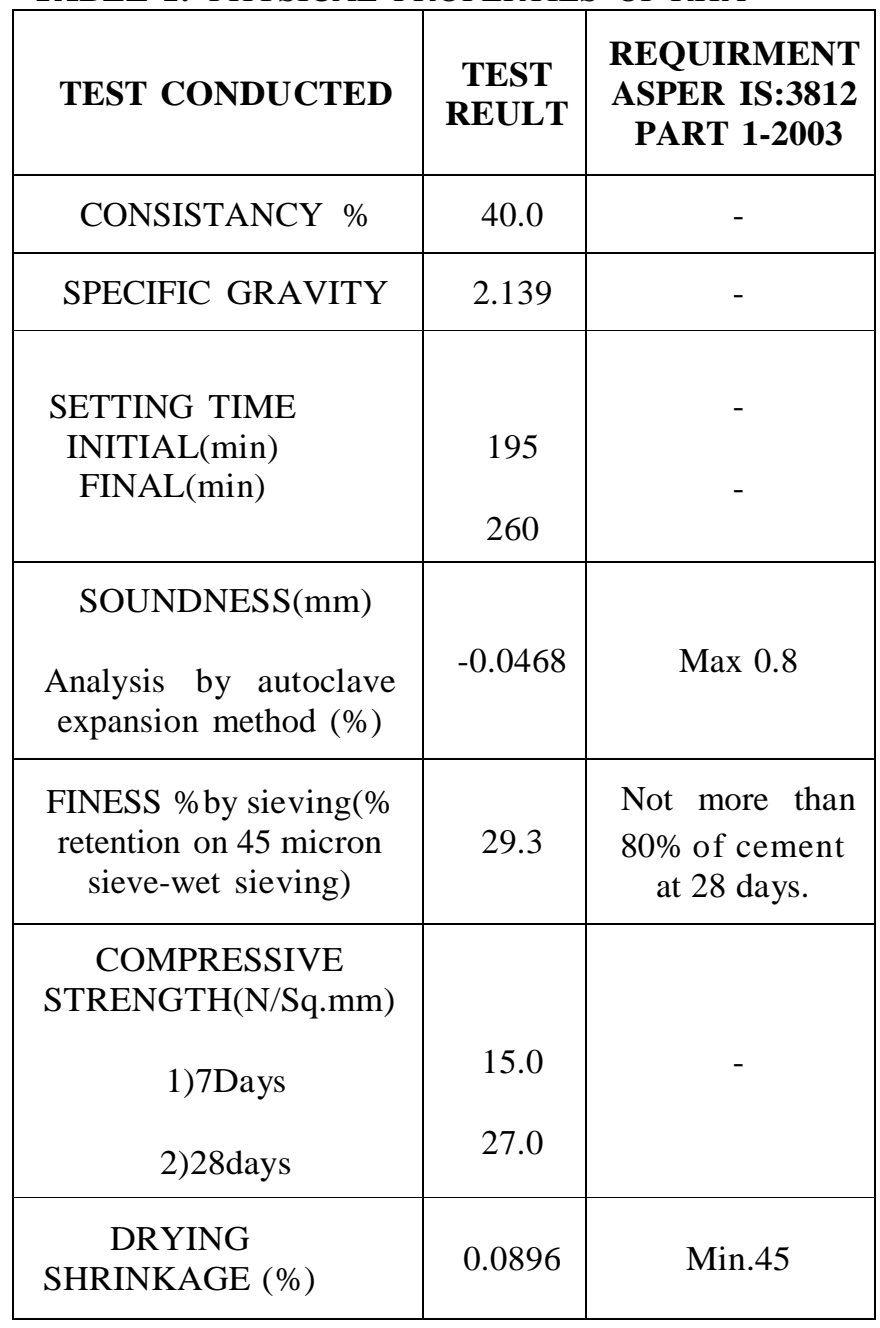

\section{C.COIR (COCONUT FIBERS):}

The coconut is the fruit of the Cocos nucifera, a tropical plant of the Arecaceae (Palmae) family.

TABLE3: MECHANICAL PROPERTIES OF COCONUT FIBER

(As per ACI 544.1R-96) Manual of concrete practice

\begin{tabular}{|l|l|}
\hline PROPERTIES & VALUES \\
\hline Fiber length(mm) & $50-110$ \\
\hline Fiber diameter(mm) & $0.1-0.406$ \\
\hline Specific Gravity & $1.12-1.15$ \\
\hline Elongation (\%) of & $2750-3770$ \\
\hline $\begin{array}{l}\text { Modulus } \\
\text { elasticity(ksi) }\end{array}$ & 150 \\
\hline $\begin{array}{l}\text { Average tensile } \\
\left.\text { strength(N/mm }{ }^{2}\right)\end{array}$ & \\
\hline
\end{tabular}

Coir fibers have higher tensile strength as compared to other natural fibers, as the coir does not break easily with hand. Coir has a high resistance against salt water. It also has good resistance against corrosion. Since it is a waste material and dumped here and there, so due to reaction with water and air it decomposes and due to which it produces bad smell, unhealthy air to breathe for human as well as for animals. Sometimes it is burned in atmosphere causing air pollution. Use of 
some of the coir fibers can reduce air pollution, and the area where extracts of coconut fruit are dumped can be maintained clean and healthy. An M20 mix is designed as per guidelines in IS 10262, 1982 based on the preliminary studies conducted in the constituent materials.

\section{D.concrete}

TABLE 4: PROPERTIES OF FRESH CONCRETE

\begin{tabular}{|c|c|}
\hline TESTS & RESULTS \\
\hline Slump Test & $116 \mathrm{~mm}$ \\
\hline Vee Bee Time & $9 \mathrm{sec}$. \\
\hline Compaction Factor Test & 0.93. \\
\hline Flow Test & $74 \%$. \\
\hline
\end{tabular}

\section{Tests on hardened concrete}

\section{1 compressive strength test:}

Three specimens for each are cast with different percentages of RHA with gradual Increase of $2.5 \%$ from $0 \%-20 \%$ by replacing the cement by weight. Table 3 shows that the strength of RHA concrete initially does not match with the strength of control specimen at 7 days and 14days but it nearly matches at 28 days and improves at 90days. The graph shows that the addition of fibers improves the compressive strength up to $15 \%$ addition of RHA after that no considerable improvement is observed. Addition of coconut fibers shows permissible results up to $3 \%$ addition.

Table5: compressive strength of concrete with rha and different percentages of coir.

\begin{tabular}{|c|c|c|c|c|}
\hline \multirow[t]{2}{*}{ MIX } & \multicolumn{4}{|c|}{$\begin{array}{c}\text { COMPRESSIVE STRENGTH } \\
\text { OF CUBES N/mm }{ }^{2}\end{array}$} \\
\hline & $\begin{array}{c}7 \\
\text { DAYS }\end{array}$ & $\begin{array}{c}14 \\
\text { DAYS }\end{array}$ & $\begin{array}{c}28 \\
\text { DAYS }\end{array}$ & $\begin{array}{c}90 \\
\text { DAYS }\end{array}$ \\
\hline M20 & 23.55 & 24.88 & 40.0 & 45.5 \\
\hline M20+2.5\%RHA & 20.11 & 20.81 & 30.18 & 42.3 \\
\hline M20+5\%RHA & 20.8 & 21.2 & 31.25 & 42.8 \\
\hline M20+7.5\%RHA & 21.22 & 21.28 & 32.58 & 43.58 \\
\hline M20+10\%RHA & 21.33 & 21.88 & 35.8 & 44.98 \\
\hline M20+12.5\%RHA & 22.5 & 22.48 & 38.55 & 45.2 \\
\hline M $20+15 \%$ RHA & 20.0 & 20.12 & 32.3 & 42.22 \\
\hline M20+17.5\%RHA & 19.98 & 19.92 & 33.3 & 41.18 \\
\hline M20+20\%RHA & 19.58 & 19.98 & 34.0 & 34.55 \\
\hline $12.5 \%$ RHA+1\%COIR & 22.8 & 23.5 & 40.8 & 36.68 \\
\hline $12.5 \%$ RHA $+2 \%$ COIR & 23.0 & 23.8 & 42.4 & 38.67 \\
\hline $12.5 \%$ RHA $+3 \%$ COIR & 23.8 & 24.4 & 42.8 & 38.07 \\
\hline $12.5 \%$ RHA $+4 \%$ COIR & 22.2 & 23.2 & 35.5 & $32 . .8$ \\
\hline $15 \%$ RHA+1\%COIR & 21.8 & 22.22 & 28.3 & 41.9 \\
\hline $15 \%$ RHA+2\%COIR & 23.5 & 28.3 & 29.4 & 35.55 \\
\hline $15 \%$ RHA+3\%COIR & 24.1 & 30.0 & 32.3 & 35.55 \\
\hline
\end{tabular}

\begin{tabular}{|c|c|c|c|c|}
\hline 15\%RHA+4\%COIR & 24.0 & 29.8 & 32.3 & 34.4 \\
\hline $17.5 \%$ RHA+1\%COIR & 22.22 & 21.87 & 30.3 & 30.3 \\
\hline $17.5 \%$ RHA+2\%COIR & 22.2 & 23.8 & 35.5 & 35.5 \\
\hline $17.5 \%$ RHA+3\%COIR & 23.5 & 28.8 & 36.8 & 36.8 \\
\hline $17.5 \%$ RHA+4\%COIR & 24.5 & 24.8 & 36.5 & 36.5 \\
\hline $20 \%$ RHA+1\%COIR & 21.1 & 21.8 & 28.0 & 28.0 \\
\hline $20 \%$ RHA+2\%COIR & 22.5 & 23.2 & 25.5 & 25.5 \\
\hline $20 \%$ RHA+3\%COIR & 23.6 & 24.2 & 26.6 & 26.6 \\
\hline $20 \%$ RHA+4\%COIR & 22.0 & 23.0 & 25.5 & 25.5 \\
\hline M20+1\%COIR & 39.11 & 44.0 & 45.33 & 48.88 \\
\hline M20+2\%COIR & 40.0 & 42.22 & 44.0 & 49.1 \\
\hline M20+3\%COIR & 41.1 & 45.5 & 46.6 & 49.9 \\
\hline M20+4\%COIR & 31.55 & 35.55 & 36.44 & 36.44 \\
\hline
\end{tabular}

GRAPH1: COMPRESSIVE STRENGTH OF CONCRETE.

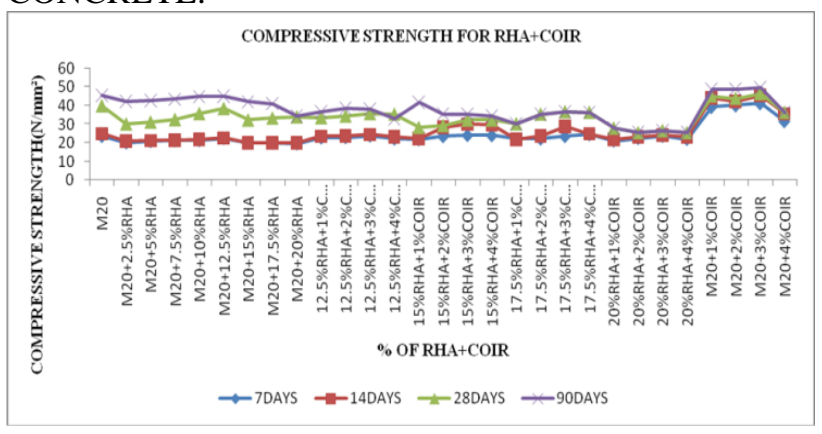

\subsection{FLEXURAL STRENGTH}

Maximum flexural strength observed at $17.5 \%$ RHA+COIR and 20\%RHA +COIR. The increase in flexural strength is observed up to $21.11 \%$. The chart shows the detail results of flexural strength test. It is also observed though the beam specimens fails to take further load but it does not break because of fibers. The fibers kept them intact and wont allow to fail easily.

\section{GRAPH 2: FLEXURAL STRENGTH OF CONCRETE}

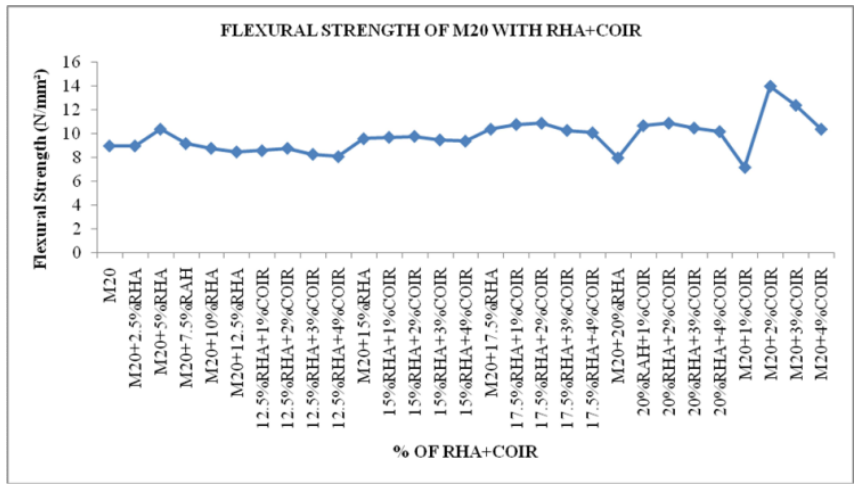


TABLE 6: FLEXURAL STRENGTH AT 28 DAYS

\begin{tabular}{|c|c|c|}
\hline SR NO & MIX & $\begin{array}{c}\text { FLEXURAL } \\
\text { STRENGTH } \\
\text { N/mm } \\
\end{array}$ \\
\hline 1 & M20 & 9 \\
\hline 2 & M20+2.5\%RHA & 9 \\
\hline 3 & M20+5\%RHA & 10.4 \\
\hline 4 & $\mathrm{M} 20+7.5 \%$ RHA & 9.2 \\
\hline 5 & M20+10\%RHA & 8.8 \\
\hline 6 & M20+12.5\%RHA & 8.5 \\
\hline 7 & M20+15\%RHA & 9.6 \\
\hline 8 & M20+17.5\%RHA & 10.4 \\
\hline 9 & M20+20\%RHA & 8 \\
\hline 10 & $12.5 \%$ RHA+1\%COIR & 8.6 \\
\hline 11 & $12.5 \%$ RHA+2\%COIR & 8.8 \\
\hline 12 & $12.5 \%$ RHA+3\%COIR & 8.3 \\
\hline 13 & $12.5 \%$ RHA+4\%COIR & 8.1 \\
\hline 14 & $15 \%$ RHA+1\%COIR & 9.72 \\
\hline 15 & $15 \%$ RHA+2\%COIR & 9.8 \\
\hline 16 & $15 \%$ RHA+3\%COIR & 9.5 \\
\hline 17 & $15 \%$ RHA+4\%COIR & 9.4 \\
\hline 18 & $17.5 \%$ RHA + $1 \%$ COIR & 10.8 \\
\hline 19 & $17.5 \%$ RHA +2\%COIR & 10.9 \\
\hline 20 & $17.5 \%$ RHA +3\%COIR & 10.3 \\
\hline 21 & $17.5 \%$ RHA +4\%COIR & 10.1 \\
\hline 22 & $20 \%$ RHA+1\%COIR & 10.7 \\
\hline 23 & $20 \% \mathrm{RHA}+2 \% \mathrm{COIR}$ & 10.9 \\
\hline 24 & $20 \% \mathrm{RHA}+3 \% \mathrm{COIR}$ & 10.5 \\
\hline 25 & $20 \%$ RHA+4\%COIR & 10.2 \\
\hline 26 & $1 \% \mathrm{COIR}$ & 7.2 \\
\hline 27 & $2 \% \mathrm{COIR}$ & 14 \\
\hline 28 & $3 \% \mathrm{COIR}$ & 12.4 \\
\hline 29 & $4 \%$ COIR & 10.4 \\
\hline
\end{tabular}

\subsection{SPLIT TENSILE STRENGTH ON CYLINDERS}

Cylinders are tested after 28 days of curing for Split Tensile Strength. The maximum strength is given by the mix of $15 \% \mathrm{RHA}+3 \%$ COIR.It is observed that the addition of RHA and COIR fibers increases the Split Tensile Strength of concrete by $46 \%$, and Coir alone increases the strength up to $44 \%$.It is also observed that at failure load the cylinders of the control specimens is split or crush very easily but the cylinders of the mix containing fibers still kept intact even after failure.

\begin{tabular}{|c|c|}
\hline MIX & $\begin{array}{c}\text { SPLIT TENSILE } \\
\text { STRENGTH OF } \\
\text { CYLINDERS N/mm² }\end{array}$ \\
\hline M20 & 4.2 \\
\hline M20+2.5\%RHA & 4.5 \\
\hline M20+5\%RHA & 4.8 \\
\hline M20+7.5\%RHA & 5.0 \\
\hline M20+10\%RHA & 5.8 \\
\hline M20+12.5\%RHA & 6.2 \\
\hline M20+15\%RHA & 6.51 \\
\hline M20+17.5\%RHA & 3.39 \\
\hline M20+20\%RHA & 2.69 \\
\hline $12.5 \%$ RHA+1\%COIR & 6.5 \\
\hline $12.5 \%$ RHA+2\%COIR & 6.8 \\
\hline $12.5 \%$ RHA $+3 \%$ COIR & 6.9 \\
\hline $12.5 \%$ RHA+4\%COIR & 6.1 \\
\hline $15 \%$ RHA+1\%COIR & 6.8 \\
\hline $15 \%$ RHA+2\%COIR & 7.2 \\
\hline $15 \%$ RHA+3\%COIR & 7.8 \\
\hline $15 \%$ RHA+4\%COIR & 7.0 \\
\hline $17.5 \%$ RHA + $1 \%$ COIR & 4.0 \\
\hline $17.5 \%$ RHA +2\% COIR & 4.42 \\
\hline $17.5 \%$ RHA +3\% COIR & 4.5 \\
\hline $17.5 \%$ RHA +4\%COIR & 4.1 \\
\hline $20 \%$ RHA+1\%COIR & 2.7 \\
\hline $20 \% \mathrm{RHA}+2 \% \mathrm{COIR}$ & 2.73 \\
\hline $20 \%$ RHA+3\%COIR & 2.8 \\
\hline $20 \%$ RHA+4\%COIR & 2.6 \\
\hline $1 \% \mathrm{COIR}$ & 6.9 \\
\hline $2 \%$ COIR & 7.3 \\
\hline $3 \% \mathrm{COIR}$ & 7.5 \\
\hline $4 \% \mathrm{COIR}$ & 6.8 \\
\hline
\end{tabular}

GRAPH 3: SPLIT TENSILE STRENGTH OF CYLINDERS AT 28 DAYS.

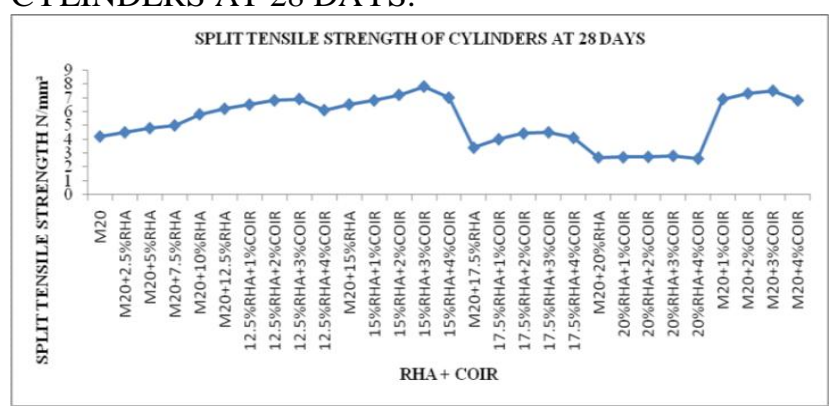

\subsection{DEFLECION TEST}

The deflection is tested while testing the flexural strength of the beam specimens. The calibrated scale is attached to the machine and the metal pointer is attached at the center of the testing specimen. The load is kept constant for testing the deflection of each specimen which is the breaking load of the control mix, it is done to show that that the addition of fibers will increase the flexural strength of the concrete and therefore at the breaking load of the control mix of the mix containing fibers and RHA the load carrying capacity is increased and the deflection is limited. 
Graph 6: deflection test on beams at 28 days

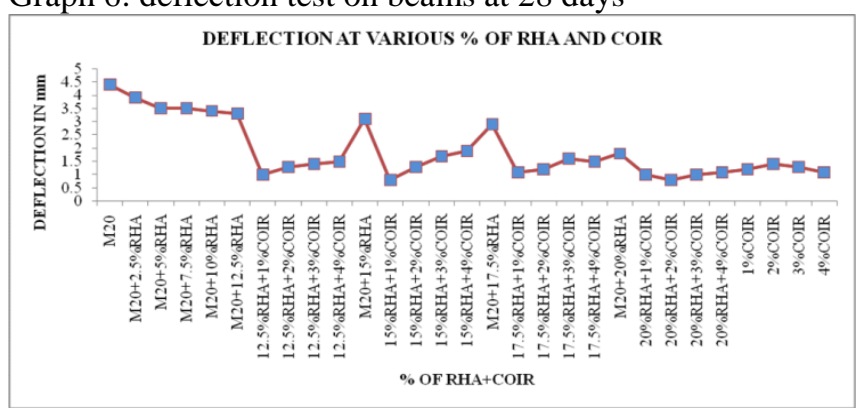

\section{4 reductions in weight of the concrete:}

It is observed that the RHA and COIR fibers has some property by which after adding it in the concrete it will reduces the weight of the concrete.RHA when added in the concrete reduces the weight of the concrete, as well as the addition of COIR fibers further reduces the weight of the concrete. Is observed during experiment Up to $25 \%$ reduction in weight. The chart shows the reduction in weight.

\section{Results:}

1. It is observed that $12.5 \% \mathrm{RHA}+2 \% \mathrm{COIR}$ gives maximum compressive strength.

2. Maximum split tensile strength and minimum deflection is also observed for the same mix.

3. Flexural strength shows maximum improvement at $20 \%$ RHA+COIR.

4. Rate analysis shows that as the percentage of RHA and COIR increases the cost goes on decreases.

5. Addition of super plasticizer improves the workability of mix.

6. Rate Analysis shows that $16 \%$ reduction in cost can be achieved.

7. Weight reduced up to $20 \%$ is observed.

\section{Conclusions:}

1. Compressive strength increases with the increase in the percentage of Rice Husk Ash up to addition of $12.5 \%$ by weight of cement

2. Concrete requires approximate increase in water cement ratio due to increase in percentage of RHA. Because RHA is highly porous material.

3. The workability of RHA concrete has been found to decrease with increase in RHA replacement.

4. It was found that rice husk when burned produced amount of silica (more than $80 \%$ ). For this reason it provides excellent thermal insulation.

5. Rice husk ash contains more silica, and hence we prefer rice husk ash use in concrete to increase the strength.
6. Though Rice husk ash is harmful for environment, but the cost of rice husk ash is zero and thus we prefer RHA use in concrete as compared to silica fumes.

7. Higher compressive strength obtained at the mix proportion of $12.5 \%$ Rha $+2 \%$ COIR.

8. At $2 \%$ and $3 \%$ COIR fiber gives maximum compressive strength.

9. After addition of COIR fibers compressive strength increased up to $3 \%-4 \%$.

10. Compressive strength of composite material is increased up to $28 \%$.

11. Flexural strength shows improvement after addition of COIR.

12. Split Tensile Strength increased up to $55 \%$.

13. Balling effect of COIR can be reduced by keep the fibers immersed in the solution of super plasticizer for 5-10mins.

\section{References}

1. Rice Husk Ash - Properties and its Uses : A Review" by A. Muthadhi, R. Anita and Dr. S. Kothandaraman .

2. "Rice Husk Ash - Properties and its Uses : A Review" by A. Muthadhi, R. Anita and Dr. S. Kothandaraman.

3. Building Materials in India: 50 years, A Commemorative Volume, Edited by T. N. Gupta, 1998.

4. Proceedings of International Training Course on, Materials design and production processes for Low Cost Housing, Trivandrum, India, $27-$ 31 March, 2001.

5. International Conference, Waste and Byproducts as Secondary Resources for Building Materials, 13-16 April, 1999, New Delhi, India.

6. Cities for all, Building Materials News, World Materials News, World Habitat Day, 4 October, 1999.

7. Proceedings of Advances in Polymeric Building Materials, 6-7 March, 2003, Roorkee, India.

8. TIFAC, News and Views, Articles, Development of Natural Fibre Composite in India.

9. IS 10262 -1981 "IS Method of Mix Design", Bureau of Indian Standards, New Delhi

10. IS 516 -1959 "Methods of Tests for strength of concrete", Bureau of Indian Standards, New Delhi

11. IS $456-2000$ "Code of Practice for Plain and Reinforced Concrete", Bureau of Indian Standards, New Delhi. 